\title{
A COMPARISON OF EFFECT OF SINGLE DOSE ANTIBIOTIC VERSUS EXTENDED ANTIBIOTIC THERAPY ON THE INCIDENCE OF POST PROCEDURE BACTERIURIA AND SYMPTOMATIC URINARY TRACT INFECTION IN PATIENTS UNDERGOING UNCOMPLICATED URETEROSCOPY
}

\author{
Shreeharsha Mallappa Awati ${ }^{1}$, Nataraj Naidu²
}

\section{HOW TO CITE THIS ARTICLE:}

Shreeharsha Mallappa Awati, Nataraj Naidu "A Comparison of Effect of Single Dose Antibiotic versus Extended Antibiotic Therapy on the Incidence of Post Procedure Bacteruria and Symptomatic Urinary Tract Infection in Patients Undergoing Uncomplicated Ureteroscopy". Journal of Evolution of Medical and Dental Sciences 2014; Vol. 3, Issue 66, December 01; Page: 14300-14308, D0I: 10.14260/jemds/2014/3918

ABSTRACT: INTRODUCTION: The necessity of antimicrobial prophylaxis for ureterorenoscopy is undisputed. Most guidelines state that single antimicrobial prophylaxis is sufficient for ureteroscopy but indiscriminate antibiotic use is common. Except for Trans Urethral Resection of Prostate and Prostate biopsy, there is a lack of well performed studies investigating the need and duration of antibiotic prophylaxis in endourology. The present study is done to know whether single dose AMP is as efficacious as multiple dose AMP for ureteroscopy. METHODS: Sixty consecutive patients undergoing uncomplicated ureteroscopy were prospectively randomized to receive single and multiple (4) doses of Ciprofloxacin. Both group patients were followed for development of bacteriuria and urinary tract infection up to one month postoperatively. RESULT: Among sixty patients, none developed either bacteriuria or urinary tract infection in the post-operative period. Conclusion: A single dose antimicrobial prophylaxis regimen is as effective as extended dose antibiotic prophylaxis in preventing the incidence of post procedure bacteriuria and symptomatic urinary tract infection in patients undergoing uncomplicated ureteroscopy.

KEYWORDS: Antimicrobial Prophylaxis, Bacteriuria, Ciprofloxacin, Infection, Ureterorenoscopy.

\section{ABBREVIATIONS:}

\begin{tabular}{|l|l|}
\hline ASA & American Society of Anesthesiology \\
\hline AMP & Antimicrobial Prophylaxis \\
\hline et al & And others \\
\hline EAU & European Association of Urology \\
\hline ICL & Intra Corporeal Lithotripsy \\
\hline Ml & Milliliter \\
\hline mg & Milligrams \\
\hline RI & Remote Infection \\
\hline SSI & Surgical Site Infection \\
\hline SMX & Sulfamethaxozole \\
\hline TURP & Trans Urethral Resection of Prostate \\
\hline TMP & Trimethoprim \\
\hline TUL & Trans Ureteral Ureterolithotripsy \\
\hline UTI & Urinary Tract Infection \\
\hline viz & They are \\
\hline
\end{tabular}




\section{ORIGINAL ARTICLE}

INTRODUCTION: Uncomplicated ureteroscopy is a clean-contaminated procedure.[1] Symptomatic urinary tract infections are possible postoperative complications of ureteroscopic interventions with the risk of ascending pyelonephritis or other inflammable complications.[2] Hence prophylactic use of antibiotic is needed during perioperative period. ${ }^{[2]}$ However indiscriminate antibiotic use increases environmental selection pressure, favoring emergence of antimicrobial resistant bacteria that can cause surgical site infections, resulting in administration of more antibiotics, an increase in the cost of care, and a prolonged hospital stay.[3]

Except for TURP and prostatic biopsy, there is a lack of well performed studies investigating the need and duration of antibiotic prophylaxis in urologic interventions. ${ }^{[4]}$ Although single dose antimicrobial prophylaxis is a widely accepted principle, still multiple dose regimens are used in some centres. ${ }^{[5]}$ So there is a need to study efficacy of single versus multiple dose antimicrobial prophylaxis in urological procedures. The present study conducted at St. Johns Medical College Hospital examined post procedure bacteriuria and post-operative UTI in patients undergoing uncomplicated ureteroscopy with patients being randomized into single versus multiple dose antimicrobial prophylaxis.

\section{MATERIALS AND METHODS:}

SOURCE OF DATA: A prospective randomized study was conducted on 60 consecutive patients undergoing uncomplicated ureteroscopy from 01.06.2012 to 31.05.2013 at a 1250 bedded tertiary care hospital in Bangalore.

\section{INCLUSION CRITERIA:}

1. Patients willing to participate in the study.

2. Patients who underwent elective uncomplicated ureteroscopic surgery for benign ureteric disease or ureteric calculus with negative pre-operative urine culture.

\section{EXCLUSION CRITERIA:}

1. Patients having clinical features of urinary tract infection.

2. Patient's under-going additional urological or other surgical procedures along with ureteroscopy or after that in the follow up period.

3. Patients who had complications during ureteroscopy such as calculus migration, ureteric perforation, ureteric avulsions and who needed ureteric stenting at the end or after procedure in post-operative period.

4. Patients not willing to be part of the study.

5. Patients allergic to ciprofloxacin.

6. Patients who were on immuno suppressants.

7. Patients who did not have complete ureteroscopy.

8. Patients undergoing ureteroscopy with ureteric stent in situ.

9. Patients suffering from remote infections.

METHOD OF COLLECTION OF DATA: This was a prospective randomized comparative study conducted over one year period. Due to time constraints limited number of patients as feasible were studied. 60 consecutive patients who were undergoing ureteroscopy for isolated ureteric calculus or 


\section{ORIGINAL ARTICLE}

other benign ureteric disease were prospectively randomized into two groups of 30 each. Groups were named as Group A and Group B.

Group A patients received a single dose of oral ciprofloxacin 500mg before ureteroscopy.

Group B patients received more than one dose (4) of ciprofloxacin $500 \mathrm{mg}$ in peri operative period. The groups were comparable in all characteristics. All patients were undergoing elective ureteroscopy. They were admitted on the day before ureteroscopy and had same pre-operative care, including fasting status, abdominal and perineal skin preparation and pre-operative medications. The patients under went ureteroscopy with same steps and with same instrument and urine was collected at the end of procedure.

The patient was continued in the study if he/she met the inclusion criteria at the end of the procedure. If a patient didn't meet the inclusion criteria at the end of procedure then he/she was excluded from the study. Since patients in both groups had same pre-operative care and had received only one dose of oral ciprofloxacin, they were alternatively placed in Group A and Group B at the end of procedure. In our hospital, ureteroscopy is done one at a time hence randomization is possible by including patients alternatively in Group A and Group B.

URETEROSCOPY- PROCEDURE: Preliminary Cystoscopy, ureterogram was done and guide wire passed into ureter. Ureteric orifice dilated using balloon dilator. The semirigid ureteroscope used was same for all patients. The ureteroscope was passed along guide wire and the pathology was treated. Pneumatic lithoclast used wherever it was necessary. Procedure was completed and bladder was emptied. No urethral catheter was placed following the procedure. Ureteroscopy was carried out by 2 consultant urologists and 3 post graduate residents under supervision of the consultants using the same 8/9.8 wolf ureteroscope. Ciprofloxacin was the antibiotic chosen for prophylaxis as recommended by guidelines, ${ }^{2,11}$ and it is the antibiotic used for prophylaxis in endourological procedures at our institute.

Patients were followed for 72 hours or up to discharge, whichever is later for development of fever or any symptoms and signs of urinary tract infection. If any of above developed, then urine culture was done. Presumptive treatment was started with a standard antibiotic and definitive treatment was given once culture report was available. All patients were followed for one month and history of development of fever, dysuria, burning micturition, increased urinary frequency and/or loin pain was obtained. Any positive history was evaluated by urine culture and appropriate treatment was given. At the end of this period or after complete resolution of symptoms, whichever was later, data was collected and analyzed using appropriate statistical tests. A case proforma was made and all relevant details were documented. Analysis was performed by using intention to treat principle. The outcome measure was rate of post procedure bacteriuria and symptomatic urinary tract infection in both groups.

The data was analyzed using appropriate statistical tests, viz, test of mean, percentage and Fisher`s exact test was used to compare the two groups and also the out-come and to arrive at $\mathrm{P}$ value. A P value of $<0.005$ was considered as significant.

RESULTS: During the time period from 01.06.2012 and 31.05.2013, a prospective randomized comparative study was conducted on 60 patients who underwent uncomplicated ureteroscopy for ureteral calculus. The 60 patients were alternatively allocated to Group A and Group B. The baseline 


\section{ORIGINAL ARTICLE}

pre-operative and post-operative data was collected of all patients and compared between both groups. Results are shown in tables 5 to 7.

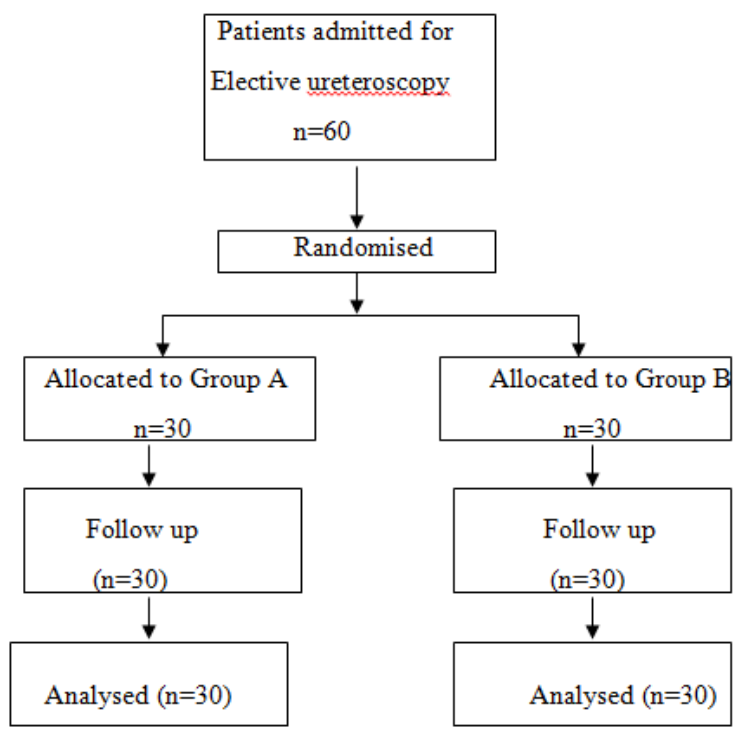

There was no statistically significant difference between the baseline clinical characteristics of patients in two groups. Since selection criteria were strict, the population was young. All patients in both groups were cases of ureteric calculus and stayed for three days in the hospital. The operative time and pneumatic lithoclast use were similar in both groups. No patients in either group had positive bacteriuria of the urine sample collected at the end of procedure. All patients had stayed in hospital for 3 days and were discharged on post-operative day 1. During follow up period of one month, no patient in either group developed urinary tract infection.

DISCUSSION: Ureteroscopic surgery is a standard procedure for various ureteral pathologies, most commonly ureteral calculi.[2] By ureteroscopy the antirefluxive barrier of the intramural ureter is bridged so that pathogens of the lower urinary tract can be protracted into the upper tract.[2] Postoperative UTIs are the main concern for morbidity in patients after ureteroscopy.[6,7] Bacteriuria, defined as bacteriuria $>10^{3}$ or $>10^{4}$ colony-forming units / $\mathrm{ml}$ in symptomatic UTI and $>10^{5} \mathrm{CFU} / \mathrm{ml}$ in asymptomatic bacteriuria within 30 days post operatively is a frequent primary outcome in urologic procedure studies.[4]

In terms of UTIs after ureteroscopy, the more current literature is fairly consistent in showing the post-operative incidence to be $<2 \%$. [8] Ureteroscopy has a risk of UTI due to several factors, including increased trauma to the mucosa, increased duration and/or degree of difficulty of most ureteroscopic procedure, increased pressure of irrigants, and manipulation or resection of infected material.[9] The necessity of antimicrobial prophylaxis for ureteroscopy is undisputed.[2,4,7,9,10,11]

Most guidelines, including AUA,[10] EAU[11] also state that a single dose AMP is sufficient for ureteroscopy. However these guidelines are not followed regularly and indiscriminate use of antibiotics is common. ${ }^{[3]}$ The present study tries to show that a single dose AMP is as efficacious as multiple doses AMP in ureteroscopy in preventing post procedure bacteriuria and post-operative UTI. 


\section{ORIGINAL ARTICLE}

Guidelines ${ }^{[11]}$ concerning perioperative prophylaxis in urological interventions have been published by Paul Ehrlich society. As recommended a fluoroquinolone was selected for this study. Ciprofloxacin was used because of its high renal excretion and peak serum concentration at 1 hour and a sufficiently long half-life (3.9 hours) ${ }^{[9]}$ as needed for ureteroscopy. Current information indicates that additional intra operative doses of anti-microbial agent should be given at intervals of one or two fold the half-life of the drug so that adequate levels are maintained throughout the operation. [3]

The use of anti-microbial agent is different from the use of other pharmaceutical agents. It is based not only on the characteristics of a patient and a drug, but also on the characteristics of the bacteria or the infection one is trying to prevent. Activity of the antibiotic is counteracted by the development of resistance by the pathogen, but also by exposed colonizing flora. Antimicrobial use is a major determinant for the development of resistance.[12] It is therefore important to optimize the use of antimicrobial drugs.[13]

Clinical guidelines are becoming increasingly popular as a means of influencing clinicians practice. This is particularly true for antibiotic usage. These aim to reduce costs of care, to control or even reduce the level of resistant organisms. [14] It is known that the practical and essential approach to the control of antibiotic resistance is to control antibiotic use. However knowledge about existing guidelines and alignment of guidelines according to current evidence is not enough to guarantee good antibiotic use in surgical prophylaxis.

The present study is a very small study done on patients who had on uncomplicated ureteroscopy. Our protocol was very simple for medical staff to implement. Most importantly, there were no significant differences in the rates of post procedure bacteriuria and post-operative UTI in both groups, in spite of a decrease in the amount of antimicrobial prophylaxis.

Moslemi MK et al[3] did a comparative evaluation of prophylactic single-dose intravenous antibiotic with postoperative antibiotics in elective urologic surgery, which included URS also. They had 74 patients in group 1 who received single intravenous cefazolin and 75 patients in group 2 who received cefazolin post operatively also. No patient in either group developed postoperative UTI and they concluded that the protocol of use of single dose antibiotic decreased the amount of antibiotics used without increasing perioperative infection rate. Takahashi $S$ et al[15] did a study to establish a standard protocol for surgical antimicrobial agents for patients who received transurethral ureterolithotripsy. They retrospectively reviewed the medical charts of patients who received TUL.

From October 2002 to December 2003, 4 doses of antimicrobial prophylaxis was done, and from January 2004 to December 2004, single prophylaxis was done. Of 135 patients with TUL, 66 were in single AMP group and 69 in 4 dose AMP group. No statistically significant difference was found in the incidence of postoperative fever between the two groups. Their study showed that single AMP was effective for patients receiving a TUL operation. Zanetti $G$ et al[16] in a review on current clinical evidence in prophylaxis and antibiotic therapy for infections and urolithiasis found excellent results with oral fluoroquinolones in prophylaxis concerning post-operative infection control after ureteroscopy. They also found that prophylaxis should be administered only for limited amount of time. Various studies $[2,3,15,17,18,19]$ have shown that a single dose of antimicrobial prophylaxis is efficacious in preventing post procedural bacteriuria and symptomatic urinary tract infection following ureteroscopy. The present study is consistent with these studies. 


\section{ORIGINAL ARTICLE}

An appealing argument for decreasing antibiotic usage may involve cost. It is obvious that a single dose of ciprofloxacin is more cost effective than multiple doses of ciprofloxacin. A single dose prophylaxis reduces costs without increasing infection rates and results in monthly cost savings. Importantly, our savings are not restricted to decreasing two to three doses per surgery, considering that over use of antibiotics may be much more expensive than the cost of the drug itself. Resistant organisms, potential allergic reactions and other adverse events related to antibiotic use will certainly cost more than just the cost of antibiotic. In countries with limited resources, such as India, even modest savings can have an impact.

In the present study, the guidelines ${ }^{[10,11]}$ were followed regarding pre-operative preparation, administration of antibiotic and post-operative follow up.

All patients had pre-operative negative urine culture and were in good general health (ASA <2) and had no other co-morbidities than ureteric calculus for which they underwent ureteroscopy. Due to time constraints the number studied was limited to 30 cases in each group. Since inclusion criteria were strict, the two groups are very similar except regarding administration of antibiotic dose. Operative time did not exceed more than 45 minutes in any case which is below half-life of ciprofloxacin (3.9 hours). All patients attended the follow up and none developed UTI.

\section{STRENGTHS OF THE STUDY:}

1. Prospectively randomized study.

2. Complete outcome data were obtained because all patients were followed upto 1 month post procedure.

\section{LIMITATIONS OF THE STUDY:}

1. Strict inclusion criteria, which excluded many patients undergoing URS.

2. Small sample size may have inadequate power to detect any significant difference in outcome.

3. Study confined to single institute and a single procedure may not reflect general patterns.

CONCLUSION: A single dose antimicrobial prophylaxis regimen is as effective as extended dose antibiotic prophylaxis in preventing the incidence of post procedure bacteriuria and symptomatic urinary tract infection in patients undergoing uncomplicated ureteroscopy.

\section{BIBLIOGRAPHY:}

1. Grabe $\mathrm{M}$ et al. Pre-operative assessment of the patient and risk factors for infectious complications and tentative classification of surgical field contamination of urological procedures. World J Urol2012; 30: 39-50.

2. Knopf HJ, Graff HJ, Schulze H. Perioperative antibiotic prophylaxis in Ureteroscopic stone removal. Eur Urol2003; 44 (1):158-164.

3. Moslemi MK, Movahed SMM, Heidari A, Saghafi H, Abedinzadeh M. Comparative evaluation of prophylactic single dose intravenous antibiotic with post-operative antibiotics in elective urologic surgery. Therapeutic and clinical risk management2010; 6: 551-556.

4. Bootsma AM, Laguna Pes MP, Geerlings SE, Goossen A. Antibiotic prophylaxis in urologic procedures: A systematic review. Eur Urol 2008 Mar 24 Epub.

5. Mc Donald M, Grabsch E, Marshal C, Forbes A. Single Versus multiple dose antimicrobial prophylaxis for major surgery: A systematic review. Aust NZ J Surg1998; 68 (6): 388-96. 


\section{ORIGINAL ARTICLE}

6. MatsumotoT, Kigota H, Matsukawa M et al. Japanese society of UTI co-operative study group. Japanese guidelines for prevention of peri operative infections in urological field. Int J Urol2007; 14: 890-909.

7. Wolf JS, Bennett CJ, Dmochowski RR et al. Best practice policy statement on urologic surgery antimicrobial prophylaxis. J Urol2008; 179: 1379-90.

8. Kau EL, Ng CS, Fuchs GJ. Complications of ureteroscopic surgery. In; Taneja SS editor, Complications of urologic surgery. Prevention and management. $4^{\text {th }}$ ed Philadelphia; Saunders 2010: P 303-316.

9. Schaeffer AJ, Schaeffer EM, Infections of the urinary tract In: Wein AJ, Kavoussi LR, Novick AC, Partin AW, Peters CA, Editors. Campbell-Walsh Urology 9th ed, Philadelphia; Saunders, 2007: P223-303.

10. Wolf JS, Bennett CJ, Dmochowski RR, Hollenbeck BK, Pearls MS, Schaeffer AJ. Best practice policy statement on urologic surgery antimicrobial prophylaxis AUA updates 2008.

11. Naber KG, Schaeffer AJ, Hynes CF et al (Eds) 2010. EAU/ International consultation on urological infections. European Association of Urology. EAU updates 2011: 78-110.

12. Swartz MN. Use of antimicrobial agents and drug resistance. N Engl J Med 1997; 337 (7): 441-6.

13. Gyssens IC. Quality measures of antimicrobial drug use. Int J Antimicrob Agents 2001; 17 (1): 9-19.

14. Brown EM. Guidelines for antibiotic usage in hospitals. J Antimicrob Chemother 2002; 49 (4): 587-92.

15. Takahashi S, Takeyama K, Miyamoto S, Tanuma Y, Takagi Y. Surgical antimicrobial prophylaxis in transurethral ureterolithotripsy. J Infect Chemother 2005; 11 (5): 239-43.

16. Zanetti G, Paparella S, Trinchieri A, Preziosa D, Francesco R, Naber KG. Infections and Urolithiasis: Current clinical evidence in prophylaxis and antibiotic therapy. Archivio Italino di Urologia e Andrologia 2008; 80(1):5-12.

17. Shigemura K, Arakawa S, Yamashita M, Yasutuku T, Fujisawa M. Surgical site infections may be reduced by shorter duration of prophylactic antibiotic medication in urological surgeries. Jpn J Infect Dis 2009; 62: 440-443.

18. Higuchi Y, Takesue Y, Yamada Y, Ueda Y, Suzuki T, Aihara K et al. A single-dose regimen for antimicrobial prophylaxis to prevent perioperative infection in urological clean and clean contaminated surgery. J Infect Chemother 2011; 17 (2): 219-23.

19. Yamamoto S, Mitsui Y, Ueda Y, Suzuki T, Higuchi Y, Qiu J et al. Assessment of single-dose regimen for antimicrobial prophylaxis to prevent perioperative infection in urologic surgery. Hinyokika Kiyo 2008; 54 (9): 587-91.

\begin{tabular}{|c|l|}
\hline Category & \multicolumn{1}{c|}{ Clinical Evaluation } \\
\hline$P_{1}$ & A normal patient \\
\hline$P_{2}$ & A patient with a mild systemic disease \\
\hline$P_{3}$ & A patient with a severe systemic disease \\
\hline$P_{4}$ & A patient with a severe systemic disease that is a constant threat to life \\
\hline$P_{5}$ & A moribund patient who is not expected to survive with or without the operation \\
\hline & Table 1: General Physical Status defined by ASA[1] \\
\end{tabular}




\section{ORIGINAL ARTICLE}

\begin{tabular}{|l|}
\hline Older age \\
\hline Deficient nutritional status \\
\hline Impaired immune response \\
\hline Diabetes mellitus \\
\hline Smoking \\
\hline Extreme weight \\
\hline Coexisting infection at a remote site \\
\hline Lack of control of risk factors \\
\hline
\end{tabular}

\section{Table 2: General patient related risk factors that may influence the risk for SSI [11]}

\begin{tabular}{|l|}
\hline Long preoperative hospital stay \\
\hline History of recurrent urogenital infections \\
\hline Colonization with microorganisms \\
\hline Long term drainage \\
\hline Urinary obstruction \\
\hline Urinary stone \\
\hline
\end{tabular}

Table 3: Special risk factors associated with increased bacterial load [11]

\begin{tabular}{|c|c|c|c|}
\hline & First choice & Alternative & Duration \\
\hline AUA Guidelines[10] & $\begin{array}{l}\text { Fluoroquinolone } \\
\text { TMP-SMX }\end{array}$ & $\begin{array}{l}\text { Aminoglycoside + Ampicillin } \\
\text { Amoxicillin }+ \text { Clavulunate } \\
1^{\text {st }} / 2^{\text {nd }} \text { generation cephalosporin }\end{array}$ & $<24$ hours \\
\hline EAU Guidelines ${ }^{[11]}$ & $\begin{array}{l}\text { TMP + SMX } \\
2^{\text {nd }} / 3^{\text {rd }} \text { Generatio } \\
\text { Amino penicillin } \\
\text { Fluoroquinolones }\end{array}$ & Cephalosporin & Single dose \\
\hline
\end{tabular}

\begin{tabular}{|c|c|c|c|}
\hline Characteristic & \multicolumn{3}{|c|}{ Patient Data } \\
\hline & $\begin{array}{c}\text { Group A } \\
\text { (n=30) }\end{array}$ & $\begin{array}{c}\text { Group B } \\
\text { (n=30) }\end{array}$ & P value \\
\hline Age (years+S.D) & $36+5.45$ & $35+5.64$ & 0.4877 \\
\hline Sex & & & \\
Male (\%) & $20(66.67)$ & $20(66.67)$ & 1.000 \\
Female (\%) & $10(33.33)$ & $10(33.33)$ & \\
\hline ASA Class & & & \\
$1(\%)$ & $24(80)$ & $24(80)$ & \\
$2(\%)$ & $6(20)$ & $6(20)$ & 1.000 \\
$>3$ & 0 & 0 & \\
\hline
\end{tabular}

Table 5: Baseline and Clinical Characteristics 


\section{ORIGINAL ARTICLE}

\begin{tabular}{|c|c|c|c|}
\hline Characteristic & \multicolumn{3}{|c|}{ Patient Data } \\
\hline & $\begin{array}{c}\text { Group A } \\
(n=30)\end{array}$ & $\begin{array}{c}\text { Group B } \\
(n=30)\end{array}$ & $P$ value \\
\hline Time (minutes +S.D) & $40+8.24$ & $38+7.58$ & 0.3319 \\
\hline $\begin{array}{c}\text { Pneumatic ICLuse } \\
\text { Yes (\%) } \\
\text { No (\%) }\end{array}$ & $\begin{array}{l}17(56.67) \\
13(43.33)\end{array}$ & $\begin{array}{l}17(56.67) \\
13(43.33)\end{array}$ & 1.000 \\
\hline
\end{tabular}

\begin{tabular}{|l|c|c|c|}
\hline \multicolumn{1}{|c|}{ Characteristic } & \multicolumn{3}{c|}{ Patient Data } \\
\hline & $\begin{array}{c}\text { Group A } \\
\text { (n=30) }\end{array}$ & $\begin{array}{c}\text { Group B } \\
\text { (n=30) }\end{array}$ & P value \\
\hline Post procedure bacteriuria & & & \\
\hline Yes (\%) & $0(0)$ & $0(0)$ & \\
\hline No (\%) & $30(100)$ & $30(100)$ & 1.000 \\
\hline $\begin{array}{l}\text { Post-operative UTI (\%) } \\
\text { (upto 30 days) }\end{array}$ & $0(0)$ & $0(0)$ & 1.000 \\
\hline \multicolumn{4}{|c|}{ Table 7: Post Procedure Details } \\
\hline \multicolumn{4}{|c|}{} \\
\hline
\end{tabular}

\section{AUTHORS:}

1. Shreeharsha Mallappa Awati

2. Nataraj Naidu

\section{PARTICULARS OF CONTRIBUTORS:}

1. Assistant Professor, Department of Urology, Sanjay Gandhi Institute of Trauma and Orthopedics, Byrasandra, Jayanagar, Bangalore.

2. Assistant Professor, Department of General Surgery, Sanjay Gandhi Institute of Trauma and Orthopedics, Byrasandra, Jayanagar, Bangalore.

\section{NAME ADDRESS EMAIL ID OF THE} CORRESPONDING AUTHOR:

Dr. Shreeharsha Mallappa Awati, Assistant Professor, Department of Urology, Sanjay Gandhi Institute of Trauma and Orthopedics, Byrasandra, Jayanagar, Bangalore-560011.

Email: awatism@gmail.com

Date of Submission: 19/11/2014. Date of Peer Review: 21/11/2014. Date of Acceptance: 27/11/2014. Date of Publishing: 28/11/2014. 